\title{
Modern Methods of Marketing Researches of Ecological Needs of Population in the Region
}

\author{
Elena Luneva ${ }^{1}$, Natalia Rebrowa ${ }^{2}$, and Olga Frik $^{3}$ \\ ${ }^{1}$ Dostoevsky Omsk State University, 644077 Mira av. 55-a, Omsk, Russia \\ ${ }^{2}$ Financial University under the Government of the Russian Federation, Omsk Branch, 644099 \\ Partizanskaya st. 6, Omsk, Russia \\ ${ }^{3}$ Siberian Institute of Business and Information Technology, 64411624 Severnaya st., 196 bl. 1 , \\ Omsk, Russia
}

\begin{abstract}
The economic damage from environmental pollution is significant; therefore, environmental protection has become an urgent problem in recent decades. The greening of the economy, the growing needs of a socio-biological nature form an environmental orientation of the interests of consumers, more and more people are aware of the importance of preserving the environment. The purpose of the article is to analyze the process of environmental awareness at the level of residents of the region, the influence of the level of development of environmental awareness of consumers on the formation and satisfaction of their environmental needs. The authors revealed the features of greening the needs of residents of the Omsk region, in the course of a marketing research, the structure of the environmental preferences of the population was determined. The choice of research methods is associated with the features of regional studies and environmental topics, to which, on the one hand, there is an increased interest among residents of the region, and on the other hand, there is a low involvement in the interviewing process.
\end{abstract}

\section{Introduction}

The development of environmentally friendly products is increasingly acting as a mechanism for differentiating goods and attracting environmentally conscious consumers in order to increase market share or receive a price premium. There is an obvious need to consider the environmental needs of people. In this connection, the problems of identification, study and assessment of environmental needs is an object of scientific research. It is necessary to understand what individual environmental needs are, how personal value orientations and environmental knowledge of consumers influence the decision to purchase. The growing social needs of a person, the system of personal value orientations are interconnected with the nature of his sociocultural activity.

Greening needs is directly related to environmental behavior and ethical consumption. Environmental behavior consists of individual actions (a set of states, specific actions, abilities and skills) and a person's attitude to actions that are influenced by goals and motives of a person (motives in their development go through the following stages: occurrence, saturation, contentment). 
Ecological behavior is a combination of specific actions and actions of people directly or indirectly associated with the impact on the natural environment, the use of natural resources. The environmental behavior of a person is determined by the characteristics of his/her environmental consciousness and basic practical skills in the field of nature management. One of the most developed theories on this issue is the theory of environmentally significant behavior, proposed by Paul C. Stern in 1995 and supplemented in 2000 [1]. Stern, P.C. focuses on the fact that several types of this behavior can be distinguished:

- pro-environmental activism (participation in pro-environmentally oriented meetings and demonstrations, etc.);

- pro-ecological non-activism in the social sphere (conscious environmental citizenship, adoption and support of pro-environmental laws and norms);

- environmentalism in private life (individual intentions and decisions made by a person in everyday life), behavior in organizations (at work, in other non-environmental organizations; behavior that may indirectly have a pro-environmental impact).

\section{Materials and Methods}

Despite the fact that most marketing research of consumer behavior in the decision-making process on the purchase of environmental products focuses on identifying the factors that determine this behavior, recently researchers have begun to study pro-ecological human behavior, including their attitude to waste management. "The human well-being depends, among other things, on the needs arising from the need for people to connect with nature in the broadest sense of the word - from the need for natural resources to aesthetic contacts with it, called human environmental needs" [2].

As one of the main aspects of the research of the category "need" is the practice of classifying them on various grounds. Common to most classical classifications are physiological and social needs. Some models also have spiritual needs and growth needs. Biological needs, those that directly depend on the environment, water, food, the availability of natural resources, temperature conditions, are primordially ecological. Human health depends on the degree of satisfaction of this group of needs. In addition, it is precisely the satisfaction of the biological (natural, urgent) needs of man, i.e. those without which the existence of man as a biological being is simply impossible, and is largely determined by the resources received by man from the environment. These needs are associated with the growth, self-preservation and development of the body. It is also worth noting that among physiological needs there are also pseudo-needs - namely, the need for luxury goods and following some habits. Pseudo-needs arise when it is impossible to satisfy physiological needs, for example, in clean water, in which case people install filters for water purification, buy bottled water. These needs are no longer physiological, are secondary or pseudorequirements in the subject of luxury [3]. Thus, there is a peculiar compensation of needs. A description of each of the needs group is presented in Tab. 1.

Table 1. The content of needs groups.

\begin{tabular}{|l|l|l|}
\hline \multicolumn{1}{|c|}{$\begin{array}{c}\text { Group } \\
\text { name }\end{array}$} & \multicolumn{1}{|c|}{ Description } & \multicolumn{1}{c|}{ Environmental needs } \\
\hline $\begin{array}{l}\text { Biological } \\
\text { needs }\end{array}$ & $\begin{array}{l}\text { They determine the survival and } \\
\text { preservation of a person's } \\
\text { physical health, for example, } \\
\text { breathing, nutrition, sleep, the } \\
\text { need for a place of residence, and } \\
\text { safety }\end{array}$ & $\begin{array}{l}\text { They include the need for clean air and water, } \\
\text { protection against diseases and anthropogenic } \\
\text { pollution, spatial comfort, comfort of the } \\
\text { natural (biogenic) environment, landscape } \\
\text { natural environment, safe and } \\
\text { environmentally friendly products. }\end{array}$ \\
\hline $\begin{array}{l}\text { Social } \\
\text { needs }\end{array}$ & $\begin{array}{l}\text { Provide social comfort. The desire } \\
\text { of a person to occupy a place in }\end{array}$ & $\begin{array}{l}\text { They include such needs as socio- } \\
\text { psychological comfort of living, the need to }\end{array}$ \\
\hline
\end{tabular}




\begin{tabular}{|l|l|l|}
\hline & $\begin{array}{l}\text { the world around him, the need for } \\
\text { self-affirmation, recognition }\end{array}$ & $\begin{array}{l}\text { be part of a community that shares } \\
\text { environmental interests, the need to be } \\
\text { recognized in society for environmental } \\
\text { merits, ideas and views. }\end{array}$ \\
\hline $\begin{array}{l}\text { Growth } \\
\text { needs }\end{array}$ & $\begin{array}{l}\text { They are connected with the } \\
\text { desire to develop and grow } \\
\text { personally, to continue to realize } \\
\text { internal potential. The need for } \\
\text { creative activity, the desire to } \\
\text { develop certain talents and } \\
\text { abilities. }\end{array}$ & $\begin{array}{l}\text { These are needs for implementation and } \\
\text { personal development in activities related to } \\
\text { environmental activities. The expression of } \\
\text { environmental ideas through creative activity. }\end{array}$ \\
\hline $\begin{array}{l}\text { Spiritual } / \\
\text { Ideal needs }\end{array}$ & $\begin{array}{l}\text { Self-knowledge, the search for } \\
\text { one's place in the world, the } \\
\text { search for the meaning of being, } \\
\text { the study of the world. }\end{array}$ & $\begin{array}{l}\text { Searching for oneself through environmental } \\
\text { activities, self-awareness as part of an } \\
\text { ecosystem. Broadcast environmental } \\
\text { principles, ideas and values, the need to } \\
\text { properly dispose }\end{array}$ \\
\hline
\end{tabular}

Environmental needs may be similar for different people, but their intensity and, therefore, the priority order of their satisfaction are not homogeneous. In this regard, there are three levels of needs:

1. The minimum level of satisfaction of the needs of existence ensures the survival of man.

2. Basic / normal level. This level can be determined by three criteria: the time that a person is occupied with certain thoughts; the actions that a person takes; the budget that a person spends on various types of activities.

3 . It is proposed that the level of luxury be considered such that satisfying the needs of existence above the basic level becomes an end in itself and / or a means of demonstrating a high social position.

Environmental needs as human values are associated with the concept of "environmental consciousness." Many researchers distinguish ecological attitudes, values, knowledge, information, pro-ecological behavior and other components in the environmental consciousness. Therefore, we can distinguishes four types of environmental awareness [4-7].

The first type is characterized by preoccupation with the current and future environmental situation, along with a willingness to pay for favorable changes and trends.

The second type differs from the first in the absence of intentions to pay for favorable trends.

The third type is focused mainly on favorable changes and believes that the state should allocate investments from tax resources.

The fourth type is characterized by ecological apathy, a low level of concern about the state of the environment.

As part of the study of this problem, the authors conducted a marketing study of the environmental needs of residents of the Omsk region (Western Siberia, Russia). The empirical research procedure was to determine the level of ecologization of the lifestyle of residents of the Omsk region, identify their environmental needs and the relationship of the consumption of environmentally friendly products with environmental awareness factors. A gamified online survey was conducted. A sample of 800 people was randomly generated (using the "snowball" method) [8-10]. The sample is formed on a territorial basis.

The choice in favor of questionnaires on the Internet was due to the high speed of data collection, which is important when conducting regional studies. If in a traditional survey, subject to the effective work of interviewers, the data is received uniformly, and then in an online survey, about $70 \%$ of all responses come in during the first day, and during the first four days - about $95 \%$. Online research does not have the problems inherent in traditional mass surveys - falsification of data by an interviewer and data entry errors. The absence of direct interaction between the researcher and the respondent in the data collection process 
allows one to avoid biases associated with the effect of the interviewer, which reduces the likelihood of receiving socially approved answers, which is very important when studying attitudes toward environmental problems. In addition, the anonymity of contacts online allows you to get detailed answers to open questions.

A measurement error in the data collection procedure during the online survey may result in incorrect interpretation or misunderstanding of the question in the questionnaire. The methods of interviewing respondents using the example of the Omsk region are shown on Fig. 1.

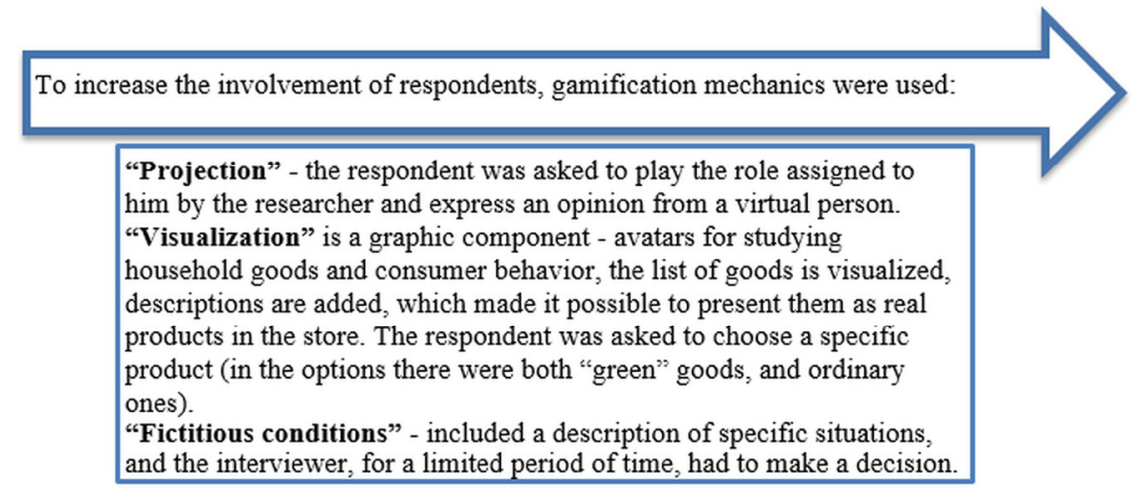

Fig. 1. Methods of interviewing respondents on example of the Omsk region.

Adding game elements to the online survey increased the interest of participants, increased the involvement of respondents, improved completion rates and data quality. Even if some respondents allow the data to be distorted, the likelihood of such falsification is not so high as to consider the results of the online survey as a whole unreliable [11]. To reduce validation errors, the results of online studies were compared with the results of similar studies in the physical environment carried out for control purposes. In the process of this study, "hard" methods of information processing were used: one-dimensional and twodimensional methods of distribution, construction of indices, factor and cluster analyzes.

\section{Results and Discussion}

The study showed that residents of Omsk mainly do not think about how production, transportation, and other manipulations with the product affect the environment. Respondents showed a rather low level of concern about the impact of their consumer practices on the environment. The respondents noted the following main ecological problems of the city: air pollution from industrial emissions, exhaust gases $(92 \%)$, the presence of landfills $(63 \%)$, and pollution of water bodies $(41 \%)$.

Most of the respondents (50.2\%) are ready to sort the waste when creating the conditions, but $92.4 \%$ of the respondents do not sort the garbage, this is due to the lack of conditions for separate collection of recyclables. It is interesting that $52.5 \%$ of respondents save resources, but at the same time, the majority is motivated by economic benefits rather than environmental concerns. At the moment, environmental safety is not a key factor affecting the consumer behavior of Omsk citizens. However, many respondents are interested in certain individual environmental practices, for example, using reusable bags (78.6\%), saving resources $(52.5 \%)$, and collecting and disposing of hazardous waste $(17.4 \%)$.

Most of the respondents $(83.6 \%)$ believe that the region has not created the necessary conditions for environmentally friendly consumption. Only $12.4 \%$ of respondents believe that some conditions are created, but they are not enough. None of the respondents believes that all the necessary conditions for environmental consumer behavior are created in Omsk. 
On the issue of Russian and foreign eco-labels, respondents showed low awareness (the average value on this issue is 1.78 on a scale of 1 to 5). The survey also showed that in Omsk consumers do not appreciate their knowledge of the laws in force in Russia that regulate the market for organic products (the average value for this issue is 1.64 on a scale of 1 to 5). Omsk residents are aware of the existence of eco-products and meet this category in the shops of the city. The responses of the survey participants showed a heterogeneous understanding of what is an "ecological product" and include healthy food and a healthy lifestyle, as well as farm and vegetarian products. The mass consumer does not have knowledge about ecolabeling, is not aware of the legal side of the issue. It follows that the consumer may be faced with Greenwashing.

The study showed that most consumers (40\%) have never thought about the environmental friendliness of the products they buy, $30 \%$ of consumers in some cases pay attention to environmental friendliness of products. Mainly this segment is made up of consumers for whom an important factor in choosing is the naturalness of the product and the absence of harmful additives. For a quarter of the respondents surveyed, the environmental friendliness of the products they purchase is not important, and they do not pay attention to it. Among the respondents there were no those who consume exclusively eco-products. Buyers (61\%) pay the most attention to the environmental friendliness of the product when purchasing food products. There is a trust problem in the eco-products market. $39.8 \%$ of respondents do not trust eco-labeling, regardless of the country of production. At the same time, consumers trust eco-labeling on foreign goods more than on Russian ones.

The factor of environmental safety and the taste of organic products are important approximately equally for respondents $(21.4 \%$ and $20 \%$, respectively). Less important factor was the status consumption and identity formation $(9 \%)$. In the "other" field, the lack of analogues among ordinary products, the desire to try something new and diversify the diet, discounts on products of this category, for comparison with ordinary products, were also indicated as a motivation to buy organic products. At the same time, the majority of consumers $(68 \%)$ purchase environmentally friendly products in supermarkets, in specialized stores $-9.8 \%$, in online stores $-7 \%$. The issue of willingness to pay for the environmental friendliness of the goods showed that the majority of consumers of eco-products $(78.4 \%)$ are ready for an increased price, but no higher than $25 \%$ compared with the same "ordinary" product. One of the reasons for the low level of consumption of environmentally friendly products by respondents noted a lack of aesthetic merits (10\%), because consumers are used to seeing bright, colorful packaging, and the use of environmental standards does not allow this.

The main reasons for the low consumption of environmentally friendly products, consumers identified a lack of trust (38\%) and too high a price (42\%). The respondents doubt that the proposed product is really environmentally friendly, as consumers are not competent enough in matters of designation of the composition of the purchased products. Also without the help of experts, they cannot reliably evaluate whether the product meets all the requirements for this category. Therefore, they cannot objectively evaluate environmental friendliness and the absence of substances harmful to the body in the products they purchase.

Only $8 \%$ of respondents believe that they have enough information to understand when buying whether they are purchasing environmentally friendly goods or not. The vast majority $(82 \%)$ believe that such information is unconditional $(50 \%)$ or rather $(32 \%)$ insufficient. When answering the question about the state of the socio-ecological environment of the city, the majority of respondents negatively assessed the sanitary condition of the streets $(63 \%)$, the level of landscaping and landscaping (57\%).

The choice in favor of more environmentally friendly, but also more expensive housing is ready to make $52 \%$ of respondents, the main category of which is the age group from 28 
to 40 years, $69 \%$ of respondents would prefer the choice of housing built using environmentally friendly building materials.

When identifying unmet needs, the answers of the respondents are as follows: clean air $(82 \%)$, environmentally friendly food $(52 \%)$, eco-friendly products for the home $(36 \%)$, environmentally friendly environmental conditions (safe and comfortable environment, including the local area), green areas $(31.2 \%)$, environmentally friendly, energy-saving and resource-saving materials, engineering equipment and systems $(28 \%)$, waste collecting and processing (26\%), waste sorting and proper disposal (20.8\%), increased life cycle product (17.2\%) (Fig. 2).

The study showed that $45 \%$ do not assume that enterprises are actually ready to produce products that fully comply with environmental requirements. This is because manufacturing enterprises do not sufficiently inform consumers about new technologies for producing goods.

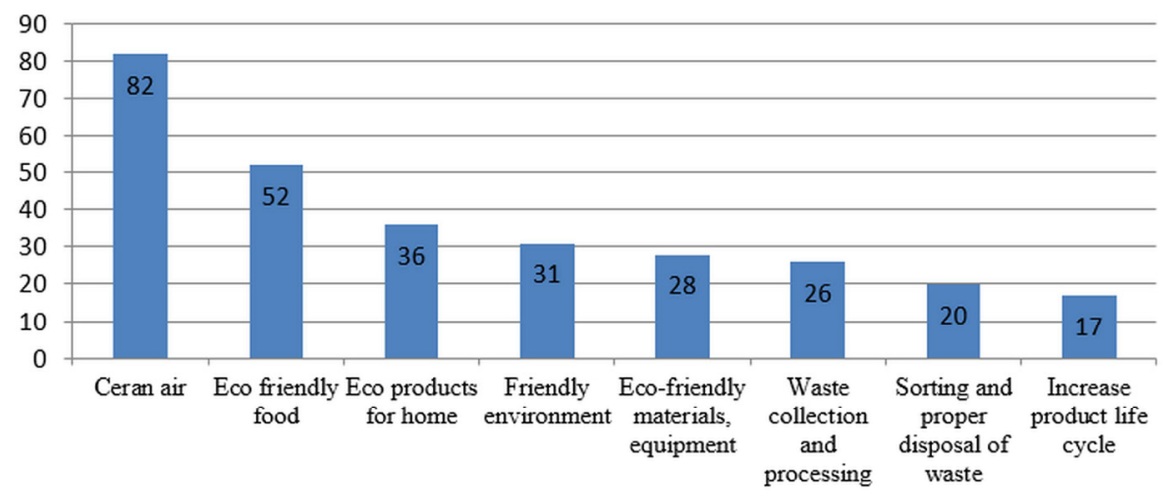

Fig. 2. Data on the responses of respondents during the study on the example of the Omsk region, $\%$.

It was determined that a sufficient part of the respondents, namely $35 \%$, believe that companies are quite ready to produce environmentally friendly and safe products, but $20 \%$ reject this assumption. According to the results of the survey, the following data was obtained on the portrait of a responsible consumer of green products - these are women (78\%), aged 18 to 35 years $(71 \%)$, with an average value of 31 years in the sample. Most eco-consumers have no children $(60 \%)$ [12].

\section{Conclusion}

The data obtained as a result of the correlation analysis showed that the environmental friendliness of consciousness, awareness of the market for organic products and the actual practices of its consumption have a significant mutual influence. Most of the questions related to these blocks reveal a significant positive correlation both within the block and with questions from the other two groups. This shows that for the development of the market of environmentally friendly products an integrated approach is needed, which would be aimed at improving the environmental awareness of residents of the Omsk region and creating conditions for pro-ecological consumer behavior.

The data obtained as a result of the study indicate a low level of environmental activism of the residents of the Omsk region, this is also due to a lack of confidence in products, insufficient environmental knowledge and conditions for environmentally friendly consumption. 


\section{References}

1. P. C. Stern, Journal of Social Issues, 56:3, 407-424 (2000)

2. E. Lowson, Environmental handbook (Penguin, London, 2001)

3. A. Nielson, The evolution of mentality: How caring for the environment leads to measurable success. Trends and Markets (Odigon Pub., New Jersey, 2018)

4. S. D. Deryabo, V. A. Yasvin, Environmental Psychodiagnostics (Ecology, Moscow, 1994)

5. V. Frolova, O. Dolina, T. Shpilkina, E3S Web Conf., 105, 01054 (2019)

6. O. Kalenov, S. Kukushkin, R. Kamanina, E3S Web Conf., 105, 04028 (2019)

7. O. Kalenov, S. Kukushkin, R. Kamanina, E3S Web Conf., 105, 04028 (2019)

8. O. Borisova, V. Frolova, L. Artamonova,E3S Web Conf., 105, 04047 (2019)

9. E. Dotsenko, N. Ezdina, E3S Web Conf., 41, 04048 (2018)

10. S. Kukushkin, O.Kalenov, E3S Web Conf., 105, 04022 (2019)

11. I. F. Devyatko, Online research in Russia 2.0 (North-East, Moscow, 2010)

12. N. P. Rebrova, Territorial marketing: a training manual (Prometheus, Moscow, 2018) 